\title{
p53 immunohistochemical staining patterns in oral squamous cell carcinoma
}

\author{
Dundy $\mathrm{G}^{1}$, Kumar $\mathrm{H}^{1}$, Singh $\mathrm{A}^{1}$, Chandrakanta ${ }^{1}$ \\ ${ }^{\text {I} D e p a r t m e n t ~ o f ~ P a t h o l o g y, ~ S a r o j i n i ~ N a i d u ~ M e d i c a l ~ C o l l e g e, ~ A g r a, ~ I n d i a ~}$
}

\author{
Keywords: \\ p53 expression, \\ Immunohistochemistry, \\ oral squamous cell \\ carcinoma, \\ Buccal mucosa
}

\begin{abstract}
Background: Mutation of p53 gene is one of the most common events in oral carcinogenesis. Accumulation of p53 protein has also been detected in premalignant lesions.

Materials and Methods: This study included 40 biopsy samples, which were received in department of pathology, Sarojini Naidu Medical College, Agra, to ascertain p53 expression by immunohistochemically, in patients with oral squamous cell carcinomas and to correlate its expression with histological grade, different sites in oral cavity and tobacco intake/smoking habits.

Results: Out of 40 biopsies of oral mucosa, 03 showed normal oral mucosa and 37 were diagnosed as squamous cell carcinoma (SCC), most patients were in 5th and 6th decade and majority (86.5\%) of oral SCC were males with buccal mucosa being the most common site. There was a statistically significant difference in $\mathrm{p} 53$ expression between oral SCC and normal oral mucosa (p value <0.05). Of total 37 cases, 12 cases were well differentiated type, 16 moderately differentiated and 09 of poorly differentiated type of SCC. In each category, about two thirds were positive for p53 staining. Out of total 37 cases of oral SCC, $64.9 \%$ were positive and $35.1 \%$ were negative for p53 expression, 34 cases had positive history of tobacco intake/smoking habits, of which 23 cases were positive while 11 cases were negative for p53 staining.
\end{abstract}

Conclusion: Abnormal p53 protein was detected in $64.9 \%$ of oral squamous cell carcinoma, but not in normal oral mucosa. p53 expression was associated with malignant transformation of oral mucosa.

\section{INTRODUCTION}

Oral cancers are one of the ten leading cancers in the world. However, in India, it is one of the most common cancers and constitutes a major public health problem. ${ }^{1}$ Oral squamous cell carcinoma is a well-known malignancy that accounts for more than $90 \%$ of all oral cancers. ${ }^{2}$ The

\section{Correspondence:}

Dr. Garima Dundy, $M D$

Department of Pathology, Sarojini Naidu Medical College, Agra, India

E-mail: garima.dundy@gmail.com tongue is the leading site, among oral cancers, in India. Other important sites in Asian countries include the buccal mucosa and gingiva. Generallyoral squamous cell carcinomas metastasize early and are associated with a poor survival rate. Their prevention largelydepends on timeous identification of precancerous oral mucosal lesions, which may present clinically as a homogeneous or nodular white plaque (leukoplakia), a mixed white and red lesion (erythroleukoplakia) or a homogeneous or nodular red lesion (erythroplakia). 


\begin{tabular}{|c|c|c|c|c|}
\hline Site & $\begin{array}{l}\text { p53 } \\
+ \text { +ve }\end{array}$ & Percentage & $\begin{array}{l}\text { p53 } \\
\text {-ve }\end{array}$ & Percentage \\
\hline Buccal mucosa $(\mathrm{n}=16)$ & 11 & $68.8 \%$ & 05 & $31.2 \%$ \\
\hline Tongue $(\mathrm{n}=05)$ & 03 & $60 \%$ & 02 & $40 \%$ \\
\hline Tonsillar area $(\mathrm{n}=03)$ & 02 & $66.7 \%$ & 01 & $32.3 \%$ \\
\hline Lips $(\mathrm{n}=03)$ & 02 & $66.7 \%$ & 01 & $32.3 \%$ \\
\hline Others $(\mathrm{n}=10)$ & 06 & $60 \%$ & 04 & $40 \%$ \\
\hline Total $(n=37)$ & 24 & $64.9 \%$ & 13 & $35.1 \%$ \\
\hline
\end{tabular}

Mechanisms to protect organisms from the consequences of DNA damage include the tumour suppressor p53 pathway. p53 protein binds specifically to a DNA consensus sequence to induce growth inhibitory genes or nonspecifically to damaged sites leading to DNA repair or apoptosis. ${ }^{3}$

The p53 gene, is a tumour suppressor gene, i.e., its activity stops the formation of tumour. Majority of human cancers demonstrate bi-allelic loss of function mutations in TP53. If a person inherits only one functional copy of the p53 gene from their parents, they are predisposed to cancer and usually develop several independent tumours in a variety of tissues in early adulthood. This condition is rare, and is known as Li-Fraumeni syndrome.The p53 gene has been mapped to chromosome 17. The amount of information that exists on all aspects of p53 normal function and mutant expression in human cancers is now vast, reflecting its key role in the pathogenesis of human cancers.

Mutation of p53 gene is one of the most common events in oral carcinogenesis. Accumulation of $\mathrm{p} 53$ protein has also been detected in premalignant lesions especially oral leukoplakia with dysplasia. This suggests that p53 gene mutation may be an early step in the malignant conversion of oral dysplastic lesions. Such patients can be identified by p53 protein specific Immunohistochemistry. ${ }^{4}$ The p53 protein is present in normal cells, and is assumed to induce G1 arrest or apoptosis in the presence of DNA lesion. The mutant protein lacks this property. Stabilization of the mutant p53 protein allows immunohistochemical analyses (IHC) to be routinely used to demonstrate the mutant p53 protein in tissue samples, whereas normal p53 protein is undetectable. $^{5}$

\section{MATERIALS AND METHODS}

The present study was based on a study carried out on 40 biopsy samples received of oral mucosa, in Department of Pathology, Sarojini Naidu Medical College. Agra, India, during the period from December 2013 to October 2015. The aim of study was to ascertain p53 expression in patients with oral squamous cell carcinomas (SCC) and to correlate its expression, with histological grade, different sites in oral cavity and history of tobacco intake/smoking habits. Prior to conduction of the study, permission was taken from ethical committee. p53 expression has been ascertained immunohistochemically. Immunohistochemistry (IHC) is an important application of monoclonal as well as polyclonal antibodies to determine the tissue distribution of an antigen of interest in health and disease. IHC is widely used for diagnosis of cancers by demonstrating specific tumour antigens that are expressed de novo or are up-regulated in certain cancers. ${ }^{6}$ Statistical analysis was performed whenever necessary.

\section{RESULTS}

The study was carried out on 40 biopsy samples received of oral mucosa; 3 were of normal oral mucosa and 37 cases were of oral squamous cell carcinoma.Patientswere from wide range of age groups, from $3^{\text {rd }}$ to $8^{\text {th }}$ decade of life. However maximum numbers of patients were from $6^{\text {th }}$ decade followed by $5^{\text {th }}$ decade. Of 37 cases of oral squamous cell carcinoma; 32 cases $(86.5 \%)$ were male and 5 cases $(13.5 \%)$ were female. Oral squamous cell carcinoma was observed to be more common in males. Buccal mucosa wasobserved as the most common site $(43.2 \%)$, followed by tongue ( $13.5 \%) .3$ patients $(8.1 \%)$ each, had lesion at tonsillar area and lips. 10 patients $(27.1 \%)$ had lesion at different sites in oral cavity such as hard palate, soft palate, retromolartrigone, gingiva, floor of mouth.

Three cases of normal oral mucosa were stained for p53 expression, all the 3 cases were negative for $\mathrm{p} 53$ staining. 37 oral squamous cell carcinoma cases were stained for p53 expression, out of which 24 (64.9\%) cases were positive and $13(35.1 \%)$ cases were negative for $\mathrm{p} 53$ staining. There was a statistically significant difference in p53 expression between oral squamous cell carcinoma and normal oral mucosa ( $\mathrm{p}$ value $<0.05$ ). Correlation of $\mathrm{p} 53$ expression in various anatomical site of oral squamous cell carcinoma is shown in table 1.

Of total 37 cases, 12 cases are termed as well differentiated squamous cell carcinoma, 16 as moderately differentiated squamous cell carcinoma and 9 of poorly differentiated squamous cell carcinoma. Out of 12 of well differentiated squamous cell carcinoma, 8 cases $(66.7 \%)$ were positive and 4 cases(33.3\%)were negative for p53 staining (fig. 1Aand 1B). Out of 16 cases of moderately differentiated squamous cell carcinoma 10cases $(62.5 \%)$ were positive and 6cases $(37.5 \%)$ were negative (fig2A and 2B)and out of 9 cases of poorly differentiated squamous cell carcinoma, 6cases $(66.7 \%)$ were positive and 3 cases $(33.3 \%)$ were negative for $\mathrm{p} 53$ staining (fig. $3 \mathrm{~A}$ and $3 \mathrm{~B}$ ).

Well differentiated and moderately differentiated,squamous cell carcinoma showed p53 staining in peripheral cells of tumor islands and lack of staining in areas of keratin pearl formation; in poorly differentiated squamous cell carcinoma, p53 showed staining of malignant nuclei. Intensity of p53 staining ranged from mild to intense among 


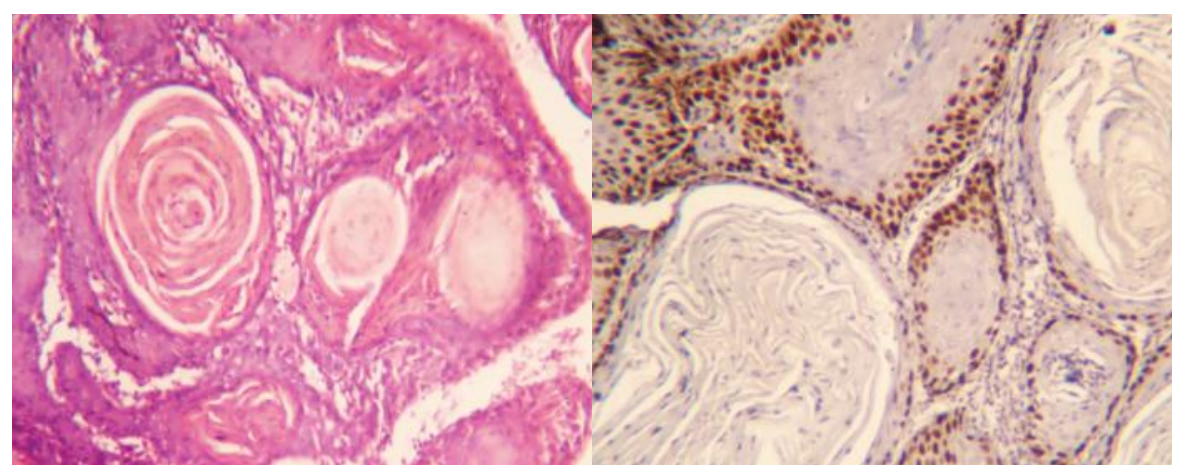

Figure 1: A: Well differentiated Squamous cell carcinoma (HE stain, X100).B: Note carcinoma showing p53 expression and negative staining in central keratinized areas (p53 IHC, X100).

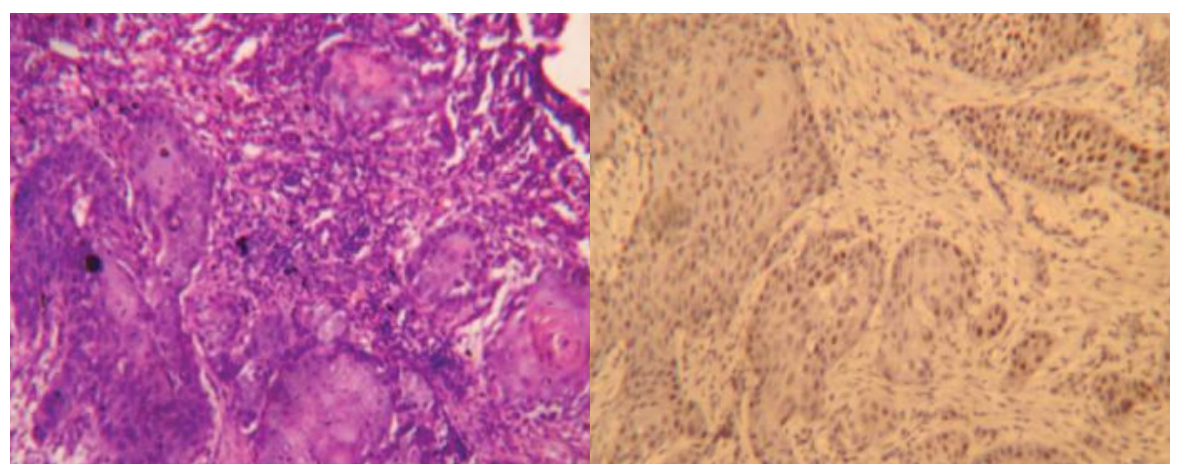

Figure 2: A: Moderately differentiated Squamous cell carcinoma (HE stain, X100).B: Note the tumor cells positively staining with p53 (p53 IHC, X100).

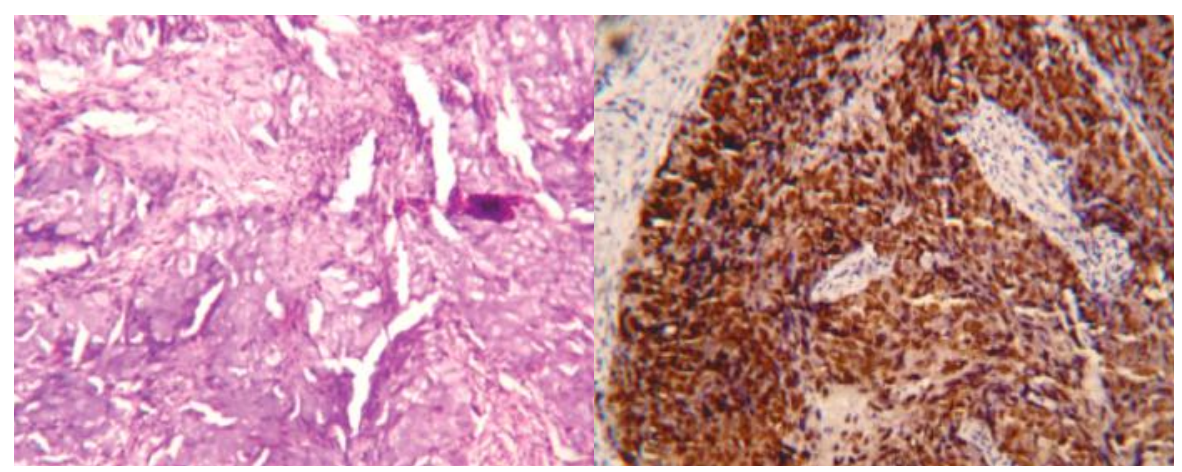

Figure 3: A: Poorly differentiated Squamous cell carcinoma (HE stain, X100).B: Note the tumor cells positively staining with p53 (p53 IHC, X100).

different cases. Cases were considered positive irrespective of intensity of staining. There was no statistical difference in 553 expression with histological grade of oral squamous cell carcinoma ( $\mathrm{p}$ value $>0.05$ ).

Out of 16 cases from buccal mucosa, 11 cases $(68.8 \%)$ were positiveand 5 cases (31.2\%) were negative for p53 staining. Out of 5 cases from tongue, 3 cases $(60 \%)$ were positive and 2 cases ( $40 \%$ ) were negative for p53 staining. Out of 3 cases each, from tonsillar area and lips, 2 cases $(66.7 \%)$ were positive and 1 case (32.3\%)was negative for p53 staining. 10 cases were from different other areas of oral cavity, out of which 6 cases $(60 \%)$ were positive and 4 cases (40\%) were negativefor p53 staining. Out of total 37 cases of oral squamous cell carcinoma 24 cases $(64.9 \%)$ were positive and 13cases (35.1\%) were negative for p53 expression. There was no statistical difference in p53 expression with different anatomical sites of oral squamous cell carcinoma ( $\mathrm{p}$ value $>0.05$ ).

Out of 37 oral squamous cell carcinoma cases, 34 cases had positive history of tobacco intake/smoking habit, of these 23 cases were positive while 11 cases were negative for p53 staining. 3 cases had no history of tobacco use/ smoking habit, of these 1 case was positive and 2 cases were negative for p53 staining. Oral squamous cell carcinoma was observed to be more common among tobacco users and smokers. Though greater percentage of cases stained positive for p53 among patients with positive history of tobacco use/smoking habit but this correlation is statistically 
insignificant ( $\mathrm{p}$ value $>0.05$ )

p53 expression was seen in 24cases (64.9\%) out of 37 cases of oral squamous cell carcinoma. Out of 12 well differentiated squamous cell carcinoma, 4 cases were negative, 1 case showed 10-50\% staining of nuclei, 7 cases showed $50-100 \%$ staining of nuclei, out of 16 cases of moderately differentiated squamous cell carcinoma, 6 cases were negative, 2 cases showed $10-50 \%$ staining of nuclei and 8 casesshowed 50-100\% staining of nuclei and out of 9 cases of poorly differentiated squamous carcinoma 3 cases were negative, 1 case showed $10-50 \%$ staining of nuclei and 5 cases showed $50-100 \%$ of nuclei.

We found that 19 cases were from age group $\leq 50$ years, out of which, 12 cases $(63.2 \%)$ were positive and 7 cases $(36.8 \%)$ were negativefor p53 staining. Out of 18 cases in age group $>50$ years, 12 cases $(66.7 \%)$ were positive and 6 cases $(33.3 \%)$ were negativefor p53 staining. There was no statistical difference in p53 expression with age of patients ( $p$ value>0.05). Out of 37 cases of oral squamous cell carcinoma, 32 were males, of these 21cases $(65.6 \%)$ were positive and 11 cases $(34.4 \%)$ were negativefor p53 staining. 5 patients were females, of these 3 cases $(60 \%)$ were positive and 2 cases $(40 \%)$ were negative for p53 staining. There was no statistical difference in p53 expression with histological grade \& different anatomical sites of oral squamous cell carcinoma, positive history of tobacco use/smoking habit, age and sex of patients. ( $p$ value $>0.05$ ).

\section{DISCUSSION}

The p53 protein is the central monitor of stress in the cell and can be activated by anoxia, inappropriate signaling by mutated oncoproteins, or DNA damage. p53 controls the expression and activity of proteins involved in cell cycle arrest, DNA repair, cellular senescence and apoptosis. ${ }^{7}$ Stabilization of the mutant p53 protein allows immunohistochemical analyses (IHC) to be routinely used to demonstrate the mutant p53 protein in tissue samples, whereas normal p53 protein is undetectable. ${ }^{6}$

In present study, aim was to find p53 expression immunohistochemically in patients with diagnosis of oral squamous cell carcinoma. Of the 40 cases included in the study, 3 cases were of normal oral mucosa and 37 cases were of oral squamous cell carcinoma. In squamous cell carcinoma 12 cases were of well differentiated squamous cell carcinoma, 16 cases were of moderately differentiated squamous cell carcinoma, and 09 cases were of poorly differentiated squamous cell carcinoma.Largest numbers of oral squamous cell carcinoma cases were from age group 51-60 years followed by 41-50 years. Oral squamous cell carcinoma was observedmore commonly (32 out of 37 cases) in males. There is significant bias in the incidence of oral cancer amongst males, which can be attributed to the easy acceptance of habits by males.
Buccal mucosa was observed as the most common site (43.2\%), followed by tongue (13.5\%).Epidemiological studies have shown that the sites of occurrence for oral cancer differ widely.

Thirty four out of 37 patients of oral squamous cell carcinoma were associated with habits of tobacco intake and smoking. Only 3 patients did not report any habit.Tobacco is easily available in India and currently tobacco and gutka is extremely accessible to all people.

Three cases of normaloral mucosawere stained for p53expression.All the cases of normal oral mucosa assessed were p53 negative. It might be due to the fact that p53 protein has shorter half-life andlow levels in normal tissue and is hard to be detected by IHC.In oral squamous cell carcinoma, 24 of total 37 cases $(64.9 \%)$ showed positive expression for p53 protein by IHC analysis. This variation in p53 expression may be due to different etiological factors and ethnic background of the patients and variation in the immunohistochemical technique used. Also tumours may have a level of p53 protein that cannot be detected by IHC.

Eight of 12 cases $(66.7 \%)$ of well differentiated squamous cell carcinoma,10of 16 cases (62.5\%) of moderately differentiated squamous cell carcinoma and 6 of 9 cases $(66.7 \%)$ of poorly differentiated squamous cell carcinoma, were positive for p53 expression. This slight difference in p53 expression with histological grade is statistically insignificant ( $p$ value $>0.05$ ). There was no association of p53 expression with histological grade of oral squamous cell carcinoma.

p53 expression was analyzed in relation to primary site of oral squamous cell carcinoma. Out of 16 cases from buccal mucosa, 11 cases $(68.8 \%)$ were positive, of 5 cases from tongue, 3 cases $(60 \%)$ were positive, of 3 cases each, from tonsillar area and lips, cases $(66.7 \%)$ were positive and out of 10 cases from different other areas of oral cavity, 6 cases $(60 \%)$ were positive for p53 staining. No significant association of primary site with p53 expression within oral cavity was observed in oral squamous cell carcinoma (pvalue>0.05).

p53 expression in oral squamous cell carcinoma patients was correlated with history of tobacco intake/smoking habit. One $(33.3 \%)$ of 3 patients with no history of tobacco use/ smoking habit and $23(67.6 \%)$ of 34 patients with positive history of tobacco intake/smoking habit showed p53 staining.Greater percentages of cases were p53 positive, in the patients with history of tobacco intake/smoking habit. However, this correlation was statistically insignificant ( $p$ value $>0.05$ ). This result needs further verification with larger sample size, and cases distributed evenly between both the groups.

Twelve cases $(63.2 \%)$ out of 19 patients with age $\leq 50$ years 
and 12 cases $(66.7 \%)$ out of 18 patients with age $>50$ years were positive for p53 staining. There was no association of p53 expression with age of patients ( $\mathrm{p}$ value >0.05). 20 $(62.5 \%)$ out of 32 male patients and $03(60.0 \%)$ out of 5 female patients were positive for p53 expression. There was no correlation of p53 expression with gender of patients ( $\mathrm{p}$ value $>0.05$ ).

\section{CONSLUSION}

Present study was undertaken to ascertain p53 expression in histologically proven cases of oral squamous cell carcinoma and to correlate its expression with histological grade, different sites in oral cavity, history of tobacco intake/ smoking habit, age and sex of the patients.

Out of total 40 cases studied, 37 cases were of oral squamous cell carcinoma and 03 cases were of normal oralmucosa. None of the normal oral mucosa was positive for p53 expression. 24of 37 cases(64.9\%) of oral squamous cell carcinoma, were positive for p53 expression. p53 expression was observed to be associated with malignant transformation of oral mucosa. 8 of 12 cases $(66.7 \%)$ of well differentiated, 10 of 16 cases $(62.5 \%)$ of moderately differentiated and 6 of $9(66.7 \%)$ cases of poorly differentiated oralsquamous cell carcinoma stained positive for p53 expression. p53 expression was not found to correlate with histological grade. No significant correlation of p53 expression withage and sex of patients, primary site of tumour and history of tobacco intake/smoking habit was found.

To conclude abnormal p53 protein was detected in $64.9 \%$ of the oral squamous cell carcinoma. p53 expression was not detected in normal oral mucosa. p53expression was observed to be associated with malignant transformation of oral mucosa. p53expression was not associated with patients age and sex, primary site of tumour, histological grade and history of tobacco intake/smoking habit.

\section{REFERENCES}

1. Shenoi R, Devrukhkar V, Sharma BK, Sapre SB, Chikhale A. Demographic and clinical profile of oral squamous cell carcinoma patients: A retrospective study. Indian journal of cancer. 2012;49:2126. Crossref

2. Feller L, Lemmer J. Oral Squamous Cell Carcinoma: Epidemiology, Clinical Presentation and Treatment. Journal of Cancer Therapy 2012;3:263-268. Crossref

3. Liu Y, Kulesz-Martin M. p53 regulation and function in normal cells and tumors. Medicina (B Aires). 2000;60:9-11.

4. Khanna R, Vidhyarthi AK, Khanna S, Singh S, Singh UC. Expression of p53 Protein in Leukoplakia and Oral Squamous Cell Carcinoma. World Journal of Surgical Medical and Radiation Oncology. 2012;1:16.

5. Duraiyan J, Govindarajan R, Kaliyappan K, Palanisamy M. Applications of immunohistochemistry. J Pharm Bioallied Sci. 2012;4:307-309. Crossref

6. Lavieille JP, Brambilla E, Riva-Lavieille C, Reyt E, Charachon $\mathrm{R}$, Brambilla C. Immunohistochemical detection of p53 protein in preneoplastic lesions and squamous cell carcinoma of the head and neck. ActaOtolaryngol. 1995;115:334-9. Crossref

7. Goh AM, Coffill CR, Lane DP. The role of mutant p53 in human cancer. J pathol. 2011;223:116-26.Crossref 